\title{
Eight methods for decomposing the energy intensity of China
}

\author{
Xiao-li Liu \\ School of Business Administration \\ North China Electric Power University, \\ Beijing, China \\ e-mail: xiaoli_lxl@sohu.com
}

\author{
Hui Huang \\ School of Business Administration, \\ North China Electric Power University \\ Beijing, China \\ e-mail: hh9719@263.net
}

\begin{abstract}
Energy intensity is crucial to the development of a society. China experienced a dramatic decline in energy intensity from the onset of economic reform in the late 1970s. Decomposition methodology is a useful analytical tool in energy consumption and energy intensity analysis, to the best of our knowledge, no decomposition study has taken into account the price index. In this paper, we use the decomposition methods derived from economic index numbers to decompose the China's energy intensity into structural change and efficiency change. The results show that technological change plays the dominant role in decreasing energy intensity in 1985-2005. According to research, the author suggests energy intensity reduction strategies should aim at structural adjustments and accelerate technological innovation.
\end{abstract}

Keywords-energy intensity, logarithmic mean divisia index decomposition method(LMID), structural effect, efficiency effect

\section{INTRODUCTION}

Energy intensity is the energy consumption per GDP output, it is a useful indicator in describing the energy used for entire production chains, and can reflect the economic structure, fuel mix, and level of technology of a country. Moreover, energy intensity is closely linked to the environment. Decreasing the energy intensity of activities is an important means by which to reduce energy-related carbon dioxide emissions in the near future (Farla et.al, 2000). China has experienced spectacular economic uprising, with $9.78 \%$ average rate growth in GDP over the period 1985-2005(NBS, 1986-2006). Against the upward trend of economy, the energy intensity showed a reversed direction of decline continuously more than 20 years from 10.91 tce/ $10^{4}$ yuan in 1985 to 5.11 tce/ $10^{4}$ yuan in 2005 . The newly approved Five-Year Plan (2006-2010) for the first time makes reduction in energy intensity a national development objective. The objective states that energy intensity will be reduced by $20 \%$ in 2010 compared with the 2005 level, which is equivalent to a reduction of $4.4 \%$ per year. It is a rather difficult task given the recent trend of increasing intensity since 2000. Without innovative measures in technology, management, as well as engagement in legislation, policy and enforcement, it might be difficult to accomplish the task. This study will contribute to examining the causes of China's energy intensity declining using the eight decomposition methods based on price index.

This paper is organized as follows. We begin with a brief introduction of China's energy situation and previous empirical studies. Section 2 briefly reviews the literature and conducts an exploratory analysis of the data. Section 3

Project Supported by National Natural Science Foundation of China (NSFC) (70671042) describes the price index methodology; Section 4 presents the empirical results for 1985-2005; finally, we conclude with a summary.

\section{LITERATURE REVIEW AND EXPLORATORY ANALYSIS}

In recent years, numerous works have been carried out on the evolution of the energy intensities in different countries. Harry (1998) studied the energy intensity change trend of Holand in 1969-1988 based on input-output method. Alcantara and Rosa (2004) analyzed the energy intensity of Europe Union based on input-output structure decompose method. Sun (2003) putted forward three modes to decrease the energy intensity, and analyzed the cause and phenomena of energy intensity decrease in some developing countries.

China's energy intensity was double that of the US and triple that of Japan in the late 1970s, and had decreased to levels more comparable to those of the US and Japan. The causes of the significant decline in China's energy intensity have been investigated by a number of decomposition studies (Huang, 1993; Sinton and Levine, 1994; Lin and Polenske, 1995; Garbaccio et al., 1999; Fisher-Vanden et al., 2003; Zhang, 2003; Chunbo and David, 2008). Many scholars have decomposed energy intensity changes into sectoral structural effect and efficiency effects. Sinton and Levine (1994) examined the relative roles of structural shift and real intensity change in China's industrial sector between 1980 and 1990. They found that real intensity change accounted for $85 \%$ of the country's overall industrial intensity change for the period 1980-1990. Lin and Polenske (1995) conducted a structural decomposition analysis to explain China's energy use changes between 1981 and 1987. Their conclusion was that, all the energy saving in China in 1987 can be attributed to energy efficiency improvements. By using survey data on approximately 2500 of China's industrial enterprises, Fisher-Vanden et al. (2003) reported that the shifts in China's industrial structure, research and development expenditures, ownership reform in the enterprise sector, and the rising relative energy prices were the principal drivers of China's declining energy intensity and consumption, and the efficiency effects at the firm level had contributed to $47 \%$ of the industrial energy intensity decline during 1997-1999. Zhang (2003) proposed decomposition method of giving no residual noted as Laspeyres of choosing the samples of China's industrial sectors from 1990 to 1997 , showed that $88 \%$ of the cumulative energy saving in the industrial sector was 
attributed to real intensity change and the $12 \%$ contribution was from structure shifts. Chunbo and David (2008) used LMDI techniques to decompose changes in energy intensity in China in the period 1980-2003 and found that technological change is confirmed as the dominant contributor to the decline in energy intensity.

However, no comprehensive and systematic studies that deal with the linkages between decomposition methods and index numbers despite their similarity in many aspects. In this paper, we first apply decomposition methods based on price index to analysis China's energy intensity changes during 1985-2005, and then some relevant conclusions and recommendations for policies are proposed.

\section{DECOMPOSITION METHOD}

Decomposition the aggregate energy indicators can be done either multiplicatively or additively. Assume that economy can be broken down to $i$ sectors, for which the energy consumption and output data are available. Subscripts 0 and $\mathrm{T}$ indicate the values of the variables in year 0 and year $T$ respectively, and the energy consumption is measured in an energy unit and industrial output in a monetary unit. All summations are taken over the $i$ sectors.

In multiplicative decomposition, we have

$$
D_{t o t}=\frac{I^{t}}{I^{0}}=D_{s t r} D_{\text {int }} D_{r s d}
$$

For methods that give perfect decomposition $D_{r s d}=1$, from the estimates of $D_{\text {str }}$ and $D_{\text {int }}$ in Equation (1), the relative contributions of structural change and sectoral energy intensity to the relative change in the aggregate energy intensity can be quantified.

Additive decomposition takes the form of

$$
\Delta I_{\text {tot }}=I^{t}-I^{0}=\Delta I_{s t r}+\Delta I_{\text {int }}+\Delta I_{r s d}
$$

If the corresponding decomposed change has a value of zero in equation (2), then a factor does not have an impact on the aggregate. For method that give perfect decomposition, $\triangle I_{r s d}=0$. Then the results may be expressed in fractional or percentage changes from the aggregate energy intensity in year 0 by decomposing $\left(\triangle I_{\text {tot }} / I^{0}\right)$ into $\left(\triangle I_{\text {str }} / I^{0}\right)$ and $\left(\triangle I_{\text {int }} / I^{0}\right)$.

Equation (1) and (2) give the governing equations for decomposing the aggregate energy intensity. The eight decomposition methods in both the multiplicative and additive forms are shown in TABLE I. They are classified into four categories, namely Group 1, Fisher ideal, Stuvel and Group 2.

\section{TABLE I FORMULAE FOR EIGHT DECOMPOSITION METHODS}

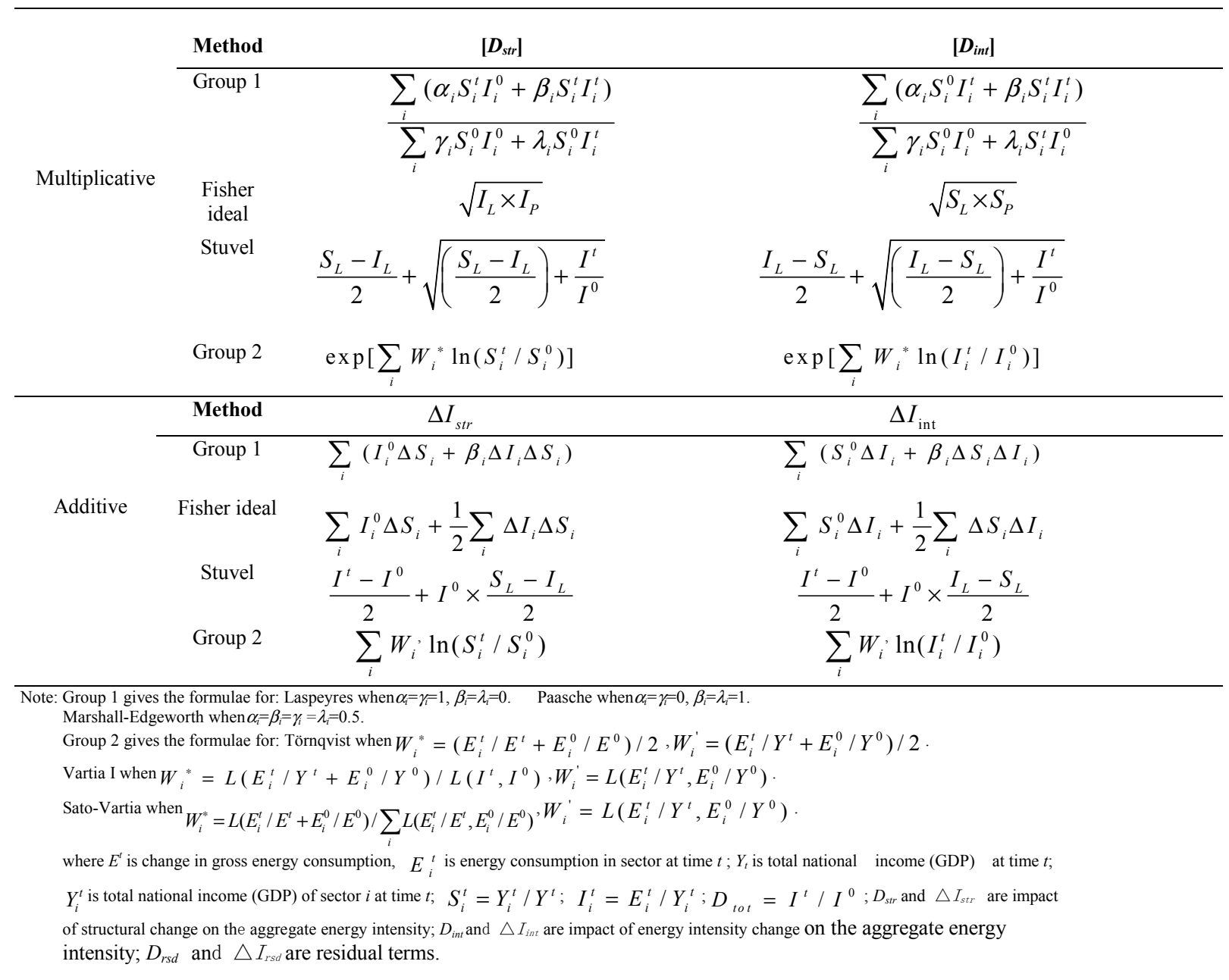




\section{RESULTS AND DISCUSSION}

This part analysis the China's energy intensity of three sectors in 1985-2005 used the above eight decomposition methods. We compiled data from various issues of the China
Statistical Yearbook (CSK) and China Energy Statistical Yearbook (CESY). The energy data and GDP data are in grams of standard coal equivalent (GSCE) and RMB Yuan respectively. The whole economy is divided into three industries: the primary, secondary, and tertiary industries. For

TABLE II DATA FOR THE ENERGY INTENSITY OF CHINA IN 1985-2005 (UNITS: MTCE, BILLION YUAN, TCE/104 YUAN)

\begin{tabular}{|c|c|c|c|c|c|c|c|c|}
\hline & \multicolumn{4}{|c|}{1985} & \multicolumn{4}{|c|}{2005} \\
\hline & $E_{i}^{0}$ & $Y_{i}^{0}$ & $S_{i}^{0} \quad(\%)$ & $I_{i}^{0}$ & $E_{i}^{t}$ & $Y_{i}^{t}$ & $S_{i}^{t} \quad(\%)$ & $I_{i}^{t}$ \\
\hline Sector 1 & 4045 & 254.16 & 28.19 & 1.592 & 7971 & 2307.04 & 12.6 & 0.346 \\
\hline Sector 2 & 52370 & 386.66 & 42.89 & 13.54 & 161468 & 8704.67 & 47.54 & 1.855 \\
\hline Sector 3 & 6950 & 260.78 & 28.92 & 2.665 & 31487 & 7296.77 & 39.85 & 0.432 \\
\hline Total & 63365 & 901.6 & 100 & 7.028 & 200926 & 18308.48 & 100 & 1.097 \\
\hline
\end{tabular}

TABLE III DECOMPOSITION RESULTS OF CHINA’S ENERGY INTENSITY IN 1985-2005 (TCE/104 YUAN)

\begin{tabular}{lcccccccc}
\hline \multicolumn{1}{c}{ Mehod } & \multicolumn{9}{c}{ Multiplicative } & \multicolumn{4}{c}{ Additive (Set 1) } \\
\hline & $D_{\text {tot }}$ & $D_{s t r}$ & $D_{\text {int }}$ & $D_{r s d}$ & $\Delta I_{\text {tot }}$ & $\Delta I_{s t r}$ & $\Delta I_{\text {int }}$ & $\Delta I_{r s d}$ \\
\cline { 2 - 8 } Laspeyres & 0.156 & 1.2169 & 0.1448 & 0.8853 & -5.93 & 0.6730 & -6.011 & -0.5923 \\
Paasche & 0.156 & 1.0782 & 0.1425 & 1.0155 & -5.93 & 0.0796 & -6.604 & 0.5946 \\
Marshall-Edgeworth & 0.156 & 1.0935 & 0.1436 & 0.9935 & -5.93 & 0.3763 & -6.307 & -0.0007 \\
Fisher Ideal & 0.156 & 1.0829 & 0.1441 & - & -5.93 & 0.3763 & -6.307 & -0.0012 \\
Stuvel & 0.156 & 1.116 & 0.1398 & - & -5.93 & 0.3763 & -6.307 & -0.0007 \\
Törnqvist & & 1.056 & 0.156 & 0.947 & -5.93 & 0.2833 & -6.026 & -0.1873 \\
Vartia I & 0.156 & 1.076 & 0.145 & - & -5.93 & 0.3121 & -6.242 & - \\
Sato-Vartia & 0.156 & 1.109 & 0.1407 & - & -5.93 & 0.3121 & -6.242 & - \\
\hline
\end{tabular}

CONTINUED TABLE III DECOMPOSITION RESULTS OF CHINA'S ENERGY INTENSITY IN 1985-2005 (\%)

\begin{tabular}{lcccc}
\hline \multirow{2}{*}{ Method } & \multicolumn{4}{c}{ Additive (Set 2) in percent change } \\
\cline { 2 - 5 } & $\Delta I_{\text {tot }} / \Delta I^{0}$ & $\Delta I_{\text {str }} / \Delta I^{0}$ & $\Delta I_{\text {int }} / \Delta I^{0}$ & $\Delta I_{r s d} / \Delta I^{0}$ \\
\hline Laspeyres & -84.376 & 9.5756 & -85.524 & -8.427 \\
Paasche & -84.376 & 1.1320 & -93.968 & 8.4601 \\
Marshall-Edgeworth & -84.376 & 5.3543 & -89.740 & 0.0099 \\
Fisher Ideal & -84.376 & 5.3538 & -89.746 & 0.0164 \\
Stuvel & -84.376 & 5.3543 & -89.740 & 0.0099 \\
Törnqvist & -84.376 & 4.0310 & -85.742 & -2.6650 \\
Vartia I & -84.376 & 4.4408 & -88.817 & \\
Sato-Vartia & -84.376 & 4.4408 & -88.817 & \\
\hline
\end{tabular}

simplicity, we assume 1985 as based year, and 2005 as year $t$, see TABEL II. The decomposition results given by the eight methods are shown in TABLE III.
Two sets of results are given for additive decomposition. In interpretation of results, we use the Fisher ideal index as an example. In multiplicative decomposition, the change in production structure leads to aggregate energy intensity for 2005 is 1.0829 times that for 1985 . However, the change in energy efficiency over the same period leads to an aggregate energy decrease for 2005 that is 0.1441 times that for 1985 . The combination of the two effects which are related multiplicatively leads to the observed drop in the aggregate energy intensity of $15.6 \%$. In additive decomposition, we refer to Set (2) results. The change in industrial structure leads to an aggregate energy intensity for 2005 that is $5.35 \%$ higher than that for 1985, while the changes in energy efficiency lead to an aggregate energy intensity decrease $89.75 \%$, the combination of the two effects lead to a drop in the aggregate energy intensity of $84.376 \%$ from $89.75 \%$. In conclusion, the technological effect dominates all the changes in energy intensity, which is consistent with the conclusions of previous empirical studies, however, the economic structure shift has not played a positive role in the energy saving but rather encouraged the increase of energy intensity. 


\section{V.CONCLUSIONS}

Since the onset of economic reform in the late 1970s, China has experienced a dramatic decline in the energy intensity of economic output. In this paper, based on the eight price index decomposition model, we decompose China's energy intensity changes during 1985-2005 into structural effect and efficiency effect. The results show that technological change plays the dominant role in decreasing energy intensity, which leads to an aggregate energy intensity decrease $89.75 \%$, while the change in industry structure leads to an aggregate energy intensity for 2005 that is $5.35 \%$ higher than that for 1985 .

In the newly formulated national $11^{\text {th }}$ Five-year Plan (2006-2010) for social and economic development, the central government firstly stipulated specific energy efficiency goal and declared to reduce the energy intensity by $20 \%$ in 2010 compared with the 2005 level. It is a rather difficult task given the recent trend of increasing intensity since 2000 . Based on the above research results, it is urgent to adjust the industrial structural and improve energy efficiency in order to accomplish the task. Industrial energy consumption in China accounted for $70.8 \%$ of the national total in 2005(NBS, $2006 \mathrm{~b})$. Reducing industrial energy intensity is crucial to the whole country's energy conservation. Hence China should jump through the mesh of heavy industrialization to a more efficiency-oriented and less resource-depleted development mode, so that more energy can be saved and a better environment can be reserved for the next generation.

In future, to save more energy, in addition to optimizing its sectoral structure and technical progress, rising relative energy prices, research and development expenditures, and ownership reform in the enterprise sector to be the principal drivers of China's declining energy intensity and use.

\section{ACKNOWLEDGMENTS}

The authors gratefully acknowledge the financial support from the National Natural Science Foundation of China under Grant No. 70671042. We also would like to thank anonymous referees for their helpful suggestions and corrections on the earlier draft of our paper according to which we improved the content.

\section{REFERENCES}

[1] Alcantara Vicent and Rosa Duarte, "Comparison of energy intensities in European Union countries, results of a structural decomposition analysis," Energy Policy, vol.32, pp.177-189,
2004.

[2] Chunbo Ma and David I. Stern, "China's changing energy intensity trend: A decomposition analysis," Energy Economics, vol.30, pp.1037-1053, 2008.

[3] Fisher-Vanden, Karen, Jefferson, Gary H., Liu, Hongmei and Tao, Quan, "What is driving China's decline in energy intensity?" Resource and Energy Economics, vol. 26, pp.77-97, 2003.

[4] Liu, F.L. and Ang, B.W. "Eight methods for decomposing the aggregate energy-intensity of industry," Energy, vol.76, pp.15-23, 2003.

[5] Garbaccio, R.F. and Ho, M.S., Jorgenson, D.W., "Why has the energy-output ratio fallen in China?" Energy Journal, vol. 20, pp.63-91, 1999.

[6] Huang, J.P., "Industrial energy use and structural change: a case study of the People's Republic of China," Energy Economics, vol. 15, pp.131-136, 1993.

[7] Sun, J.W. "The decrease in the difference of energy intensities between OECD countries from 1971 to 1998," Energy Policy, vol. 30, pp. 631-635, 2002.

[8] Farla, J.C.M. and Blok, K. "The use of physical indicators for the monitoring of energy intensity developments in the Netherlands 1980-1995," Energy, vol.25, pp. 609-638. 2000.

[9] Jonathan E. Sinton and Mark D.Levine, "Changing energy intensity in Chinesd industry:The relatively importance of structural shift and intensity change, " Energy Policy, vol. 22, pp.239-255,1994.

[10] Lin, X. and Polenske, K.R., "Input-output anatomy of China's energy use changes in the 1980s," Economic Systems Research, vol. 7, pp. 67-84, 1995.

[11] Sun, J.W., "Three types of decline in energy intensity an explanation for the decline of energy intensity on some developing countries," Energy Policy, vol.31, pp. 519-526, 2003.

[12] State Statistic Bureau, China Energy Statistic Yearbook 2006. China Statistic Press, Beijing.

[13] Zhang, Z.X., "Why did the energy intensity fall in China's industry sector in the 1990s? The relative importance of structural change and intensity change," Energy Economics, vol. 25, pp. 625-638, 2003.

[14] Harry C. Wilting, Wouter Biesiot and Henri C. Moll, "Trends in Dutch energy intensities for the period 1969-1988," Energy, vol. 23, pp. 815-822, 1998. 